\title{
ACS \\ Highly Efficient Removal of Silver-Containing Nanoparticles in Waters by Aged Iron Oxide Magnetic Particles
}

\author{
Xiao-xia Zhou, ${ }^{\dagger+}$ Ying-jie Li, ${ }^{\dagger, \S}$ and Jing-fu Liu* ${ }^{* \dagger, \ddagger \odot}$ \\ ${ }^{\dagger}$ State Key Laboratory of Environmental Chemistry and Ecotoxicology, Research Center for Eco-Environmental Science, Chinese \\ Academy of Sciences, Beijing 100085, China \\ ${ }^{\ddagger}$ University of Chinese Academy of Sciences, Beijing 100049, China \\ ${ }^{\S}$ College of Chemistry and Chemical Engineering, Henan Polytechnic University, Jiaozuo 454000, China
}

\section{Supporting Information}

ABSTRACT: Methods for the removal of silver nanoparticles (AgNPs) and their transformation products, silver-containing nanoparticles (AgCNPs), are important, because of their potential risks to the general population and the environment. In this study, aged iron oxide magnetic particles (IOMPs) were synthesized by a simple solvothermal reaction and used for the removal of AgCNPs. The prepared IOMPs exhibit a high adsorption capacity toward AgCNPs in aqueous medium. Kinetic studies indicated that the adsorption of AgCNPs is a pseudo-second-order process. The experimental data for the

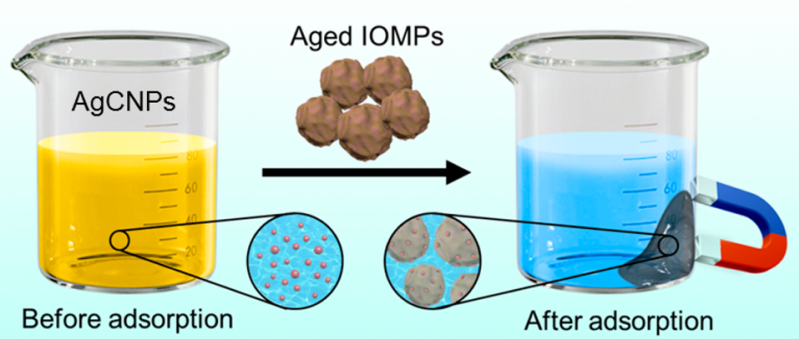
adsorption of AgCNPs follow the Langmuir isotherm model, and their maximum adsorption capacities were $19.9-62.8 \mathrm{mg} / \mathrm{g}$ at pH 6.2 and $298 \mathrm{~K}$. The sorption mean free energy calculated by the Dubinin-Radushkevich isotherm was $4.09-5.17 \mathrm{~kJ} / \mathrm{mol}$, indicating the occurrence of physisorption, which was mainly due to the electrostatic interactions. The IOMP adsorbents maintained high removal efficiencies after four cycles of adsorptiondesorption, suggesting good reusability of the developed IOMPs. Moreover, good removal efficiencies $(63.3 \%-99.9 \%)$ and recoveries $(67.1 \%-99.9 \%)$ were obtained from the real samples spiked with AgCNPs at levels of $10 \mu \mathrm{g} / \mathrm{L}$, showing that the aged IOMPs could be used as efficient and low-cost adsorbents for the removal and recovery of AgCNPs from real waters.

KEYWORDS: Aged iron oxide magnetic particles, Adsorption, Silver-containing nanoparticles, Removal, Waters

\section{INTRODUCTION}

Because of the excellent electro-optical, antimicrobial, and catalytic properties, silver nanoparticles (AgNPs) have many applications in sensing, ${ }^{1}$ catalysis, ${ }^{2}$ antimicrobial products, ${ }^{3}$ and water treatment. ${ }^{4}$ However, the growing use of consumer products incorporated with AgNPs leads to their increasing release into the environment. ${ }^{5-7}$ Since AgNPs are far from being chemically inert, once they entered the environment, they have been shown to react with Ag-complexing ligands (i.e., organic matter, sulfur, chlorine) to form various Ag-containing NPs (AgCNPs), such as $\mathrm{AgCl} \mathrm{NPs}$ and $\mathrm{Ag}_{2} \mathrm{~S}$ NPs. ${ }^{8-10}$ There are many studies on toxicity and envirronmental safety of AgCNPs to various aquatic organisms in different trophic levels, such as microorganisms, ${ }^{11-13}$ algae, ${ }^{14}$ macrophytes, ${ }^{15,16}$ and fishes. ${ }^{17}$ In vitro studies demonstrated that AgCNPs can damage mammallian cells and their DNA. ${ }^{18}$ Also, in vivo studies with AgCNPs showed their bioaccumulation in important body organs, including the lungs, liver, kidneys, and brain, which has adverse impacts and hazards on mammals. ${ }^{19}$ Moreover, several studies have demonstrated the transfer and biomagnification of AgCNPs in a food chain. ${ }^{20-22}$ At present, AgCNPs have been considered as one of the most important pollutants, and the related researches are becoming hotspots in the field of environmental science. ${ }^{23,24}$ Thus, the issue of environmental remediation of AgCNPs must be urgently addressed.

A variety of approaches have been available for the removal of NPs, including chemical coagulation, ${ }^{25}$ membrane filtration, ${ }^{26,27}$ biological processes, ${ }^{28}$ and cloud point extraction. ${ }^{29}$ Adsorption is a very promising method for the removal of NPs from environmental waters, because of its simplicity and costeffective nature. However, limited adsorbents including polymers, ${ }^{30,31}$ carbon spheres, ${ }^{32}$ hybrid material, ${ }^{33}$ and metal oxides $^{34}$ have been proposed for the removal of AgNPs from various water samples. Magnetic particles are excellent adsorbents for the removal of pollutants from waters, because they can be easily separated after binding and require little energy. ${ }^{35}$ Iron oxide magnetic particles (IOMPs) have been widely used in the purification, because of their cost-effective preparation, large surface area, good biocompatibility, and low toxicity. ${ }^{36,37}$ However, the use of IOMPs for the removal of AgNPs has not been reported.

Received: March 15, 2017

Revised: April 7, 2017

Published: April 12, 2017 
In our previous work, aged IOMPs $\left(\mathrm{Fe}_{3} \mathrm{O}_{4}\right.$ magnetic particles) were used for speciation analysis of $\mathrm{Ag}_{2} \mathrm{~S}$ NPs in environmental waters. ${ }^{38}$ The optimum conditions for AgCNP extraction were obtained by investigating the factors, including $\mathrm{pH}$, extraction time, amount of humic acid, the coatings, and sizes of the AgCNPs. While pristine IOMPs can also effectively extract AgCNPs from water, the stability and oxidization capability of the adsorbents was significantly increased after aging. Meanwhile, the high saturation magnetization ensured their separation within $\sim 1$ min after extraction. Therefore, the aged IOMPs show promise as a potential new adsorbent for the removal of AgCNPs. However, whether the aged IOMPs can serve as an adsorbent for the removal of AgCNPs in practical applications is still determined by the adsorption performance in engineering point of view, including the adsorption capacity and adsorption rate, which are crucial factors for designing adsorption reactors, and controlling the cycle period of a fixed bed adsorption process, as well as optimizing working conditions. In addition, to cut the costs during practical wastewater treatment, high desorption ability after adsorption and good reuse performance are required for an excellent adsorbent. In our previous work, the key issues of the adsorption kinetics, adsorption isotherm, and regeneration of the adsorbents have not been studied yet. Moreover, the applicability in removal of AgCNPs from real waters with complex matrices remains to be verified.

The objective of this work is to study the use of aged IOMPs for the removal of AgCNPs from waters. Using the four most predominant AgCNPs in the environment (AgNPs, ${\mathrm{Ag} \& \mathrm{Ag}_{2} \mathrm{~S}}$ $\mathrm{NPs}, \mathrm{Ag}_{2} \mathrm{~S}$ NPs, and $\mathrm{AgCl} \mathrm{NPs}$ ) as models, the sorption kinetics were analyzed using pseudo-first-order, pseudo-second-order, intraparticle diffusion, and Elovich models, while the adsorption isotherm was identified using Langmuir, Freundlich, and Dubinin-Radushkevich isotherms. The reusability and applicability of the aged IOMPs in real waters were also investigated.

\section{EXPERIMENTAL SECTION}

Chemicals and Materials. Aqueous dispersions of AgNPs with unknown coating were obtained from Shanghai Huzheng Nanotechnology Co. Ltd. (Shanghai, China). A series of citrate-coated and poly(vinylpyrrolidone) (PVP)-coated AgNPs with nominal sizes of 10 $( \pm 2), 30( \pm 3), 40( \pm 4), 60( \pm 4) \mathrm{nm}$, respectively, were obtained from nanoComposix (San Diego, CA). $\mathrm{NiO}(<30 \mathrm{~nm})$ and $\mathrm{ZnO}$ NPs $(30 \mathrm{~nm})$ with unknown coatings were purchased from Sigma-Aldrich (St. Louis, MO) and Aladdin Chemistry Co., Ltd. (Shanghai, China), respectively. Their zeta potentials measured by dynamic light scattering (DLS) were $34.3 \mathrm{mV}(\mathrm{ZnO} \mathrm{NPs})$ and $32.6 \mathrm{mV}(\mathrm{NiO}$ NPs), respectively (Table S1 in the Supporting Information). Silver nitrate and bis(p-sulfonatophenyl)phenylphosphane dehydrate dipotassium salt (BSPP) were obtained from Sinopharm Chemical Reagent Co., Ltd. (Beijing, China). Thiourea was obtained from SigmaAldrich (St. Louis, MO). All other chemicals were obtained from Beijing Chemicals (Beijing, China). All chemicals were used as received without additional purification. Ultrapure water (18.2 $\mathrm{M} \Omega$ ) from a Milli-Q Gradient System (Millipore, Bedford) was used in the entire experimental process.

Ag\& $\mathrm{Ag}_{2} \mathrm{~S}$ NPs (transformed from AgNPs with $\mathrm{S}^{2-}$, containing mostly $\mathrm{Ag}_{2} \mathrm{~S}$ NPs and some $\mathrm{Ag} @ \mathrm{Ag}_{2} \mathrm{~S}$ NPs with a Ag core and $\mathrm{Ag}_{2} \mathrm{~S}$ shell), $\mathrm{Ag}_{2} \mathrm{~S}$ NPs, and $\mathrm{AgCl} \mathrm{NPs}$, were prepared according to the details described in the Supporting Information.

Synthesis of IOMPs. The IOMPs were prepared through a solvothermal reaction with minor modification. ${ }^{39,40}$ Briefly, $2.7 \mathrm{~g}$ of $\mathrm{FeCl}_{3} \cdot 6 \mathrm{H}_{2} \mathrm{O}$ was vigorously stirred in $100 \mathrm{~mL}$ of ethylene glycol to form a clear solution. Then, $7.2 \mathrm{~g}$ of sodium acetate was all added at once and stirred at $1500 \mathrm{rpm}$ for $20 \mathrm{~min}$. The obtained solution was transferred into a Teflon-lined stainless-steel autoclave, sealed, and heated at $200{ }^{\circ} \mathrm{C}$ for $10 \mathrm{~h}$. The products were collected using a permanent magnet and washed sequentially with ethanol and ultrapure water several times to remove nonmagnetic byproducts, and the clean products were dried under vacuum at $60{ }^{\circ} \mathrm{C}$ for $6 \mathrm{~h}$. Finally, the dried microspheres were aged at $90{ }^{\circ} \mathrm{C}$ overnight. Note that, although the solvothermal reaction must be carried out under high temperature and high pressure, it has been widely applied in the large-scale industrial production of various functional nanoparticles, such as $\mathrm{TiO}_{2} \mathrm{NPs}$ and graphene. ${ }^{41,42}$

TEM Characterization. Transmission electron microscopy (TEM) was conducted with a TEM system (Model H-7500, Hitachi, Japan) operated at $80 \mathrm{kV}$. TEM samples were prepared by dripping $5 \mu \mathrm{L}$ of the NP sample solution onto a carbon-coated TEM grid $(\mathrm{Cu}, 200$ mesh, Zhongxingbairui Technology Co. Ltd., Beijing, China) and drying at room temperature under vacuum. The particle number size distribution was calculated by counting at least 160 particles with Nano Measurer 1.2 software.

SEM Characterization. Field-emission scanning electron microscopy (FE-SEM) (Model SU8010, Hitachi) was conducted for surface morphology and size investigations. Powders were loaded on silicon slices, and SEM images were recorded at an operation voltage of 3.0 $\mathrm{kV}$.

DLS Characterization. The hydrodynamic diameters and polydispersity index of each NP sample were measured by dynamic light scattering (DLS) with a Malvern Nano ZS instrument (Malvern Instruments, Ltd., U.K.) using $2 \mathrm{~mL}$ of $1 \mathrm{mg} / \mathrm{L} \mathrm{NP}$ suspension in a macrocuvette (pass length $=1 \mathrm{~cm}$ ). The scattering angle was $173^{\circ}$, and the temperature was maintained at $25^{\circ} \mathrm{C}$. The refractive index (RI) for the NPs was 1.07 and the adsorption value was 0.01. Each DLS measurement was performed for 30 acquisitions and the DLS characterization of each sample was repeated three times. The same instrument was used to determine the zeta potential of each sample.

XRD Characterization. The crystal structure of pristine and aged IOMPs was examined with a MSAL-XD2 X-ray diffractometer (X'Pert Pro instrument, Panalytical) using $\mathrm{Cu} \mathrm{K} \alpha$ radiation $(\lambda=0.1541 \mathrm{~nm})$ ranging from $10^{\circ}$ to $90^{\circ}(2 \theta)$ at $30 \mathrm{kV}$ and $30 \mathrm{~mA}$.

Adsorption Kinetic Study. Kinetic studies were conducted by adding $20 \mathrm{mg}$ of the as-prepared aged IOMPs $(0.2 \mathrm{~mL}$ of $100 \mathrm{mg} / \mathrm{mL}$ aqueous dispersions) into $100 \mathrm{~mL}$ of $20 \mathrm{mg} / \mathrm{L} \mathrm{AgCNP}$ solution. At scheduled time (5-90 min), $0.2 \mathrm{~mL}$ of water sample was collected for the determination of the residual AgCNP concentration. The adsorption capacity at time $t_{i}, Q_{t_{i}}(\mathrm{mg} / \mathrm{g})$, was calculated by ${ }^{43}$

$$
Q_{t_{i}}=\frac{\left(C_{0}-C_{t_{\mathrm{i}}}\right) V_{0}-\sum_{2}^{i-1} C_{t_{\mathrm{i}}} V_{s}}{m}
$$

where $C_{0}(\mathrm{mg} / \mathrm{L})$ is the initial AgCNP concentration, $C_{t_{i}}(\mathrm{mg} / \mathrm{L})$ is the AgCNP concentration at time $t_{i}, V_{0}(\mathrm{~L})$, and $V_{s}(\mathrm{~L})$ are the respective volume of the AgCNP solution and the AgCNP solution collected for analysis, and $m(\mathrm{~g})$ is the mass of the aged IOMPs.

Adsorption Isotherm Study. AgCNP working solutions (100 $\mathrm{mL}$ ) with initial concentrations in the range of $0.01-15 \mathrm{mg} / \mathrm{L}$ were prepared by serial dilution of a stock solution. The $\mathrm{pH}$ then was adjusted to 6.2 with $\mathrm{HAc} / \mathrm{NaAc}$ buffer solution $(1 \mathrm{M})$ and the $\mathrm{Ca}^{2+}$ concentration was adjusted to $10 \mathrm{mM}$ with $1 \mathrm{M} \mathrm{Ca}\left(\mathrm{NO}_{3}\right)_{2}$. Finally, 20 $\mathrm{mg}$ of the as-prepared aged IOMPs $(0.2 \mathrm{~mL}$ of $100 \mathrm{mg} / \mathrm{mL}$ aqueous dispersions) was added. Experiments were carried out at room temperature in covered polyethylene terephthalate (PET) bottles and shaken using a platform shaker (IKA KS501) at $300 \mathrm{rpm}$ for $20 \mathrm{~min}$. The aged IOMPs were then separated from the AgCNP solution using a permanent magnetic. The concentration of silver in supernatant was determinted by inductively coupled plasma- mass spectrometry (ICPMS) (Model $7700 \mathrm{cs}$, Agilent). The adsorption capacity $\left(Q_{e}, \mathrm{mg} / \mathrm{g}\right)$ can be expressed as eq 2 :

$$
Q_{\mathrm{e}}=\frac{\left(C_{0}-C_{\mathrm{e}}\right) V}{m}
$$



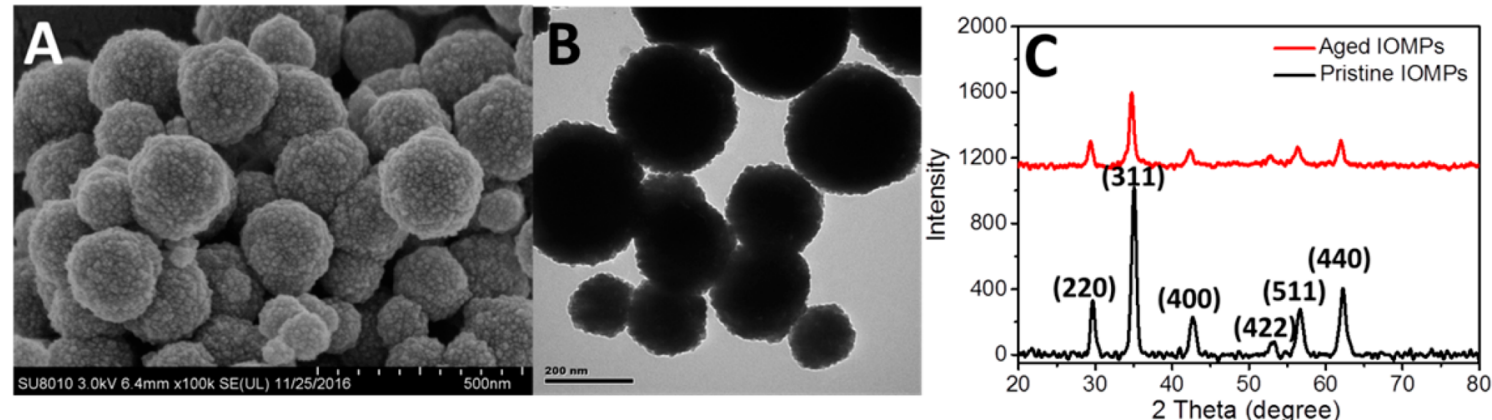

Figure 1. Characterization of IOMPs: (A) SEM image of aged IOMPs, (B) TEM image of aged IOMPs, and (C) XRD patterns of pristine and aged IOMPs.
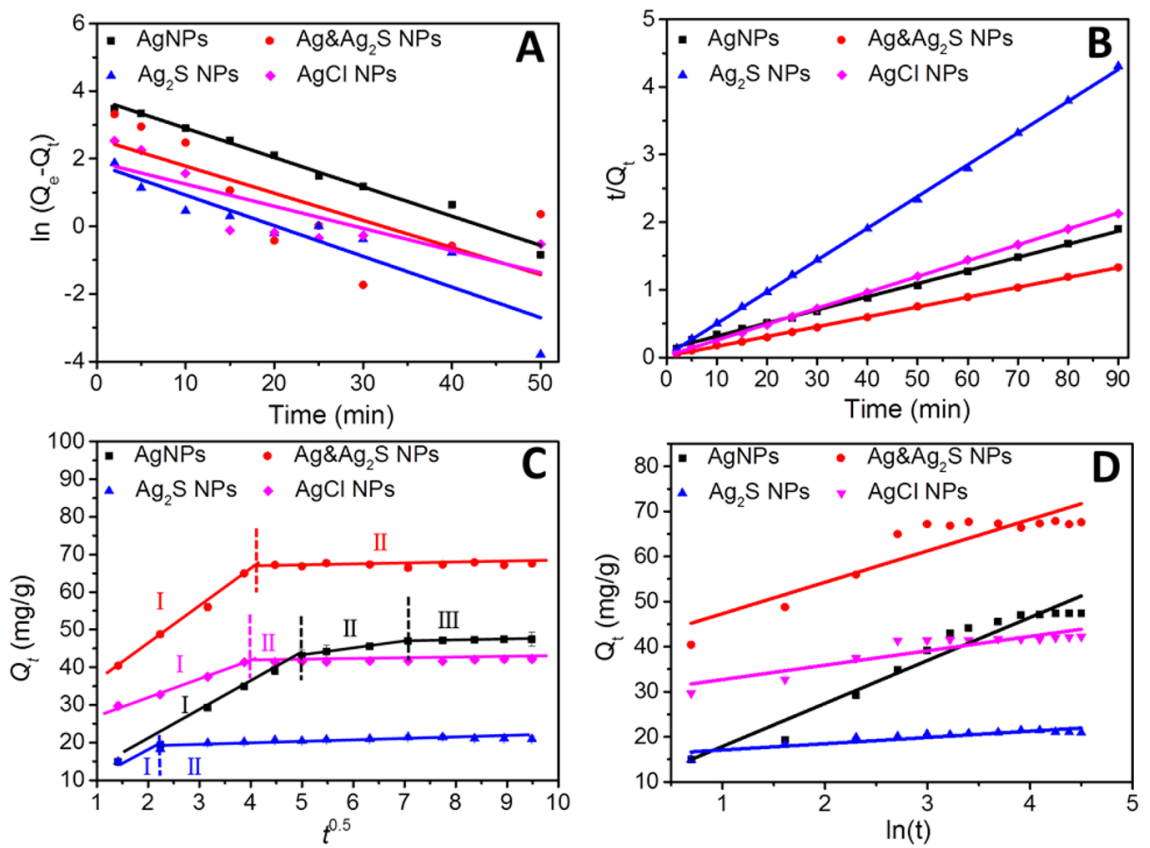

Figure 2. Fitting of different kinetic models to AgCNP adsorption by aged IOMPs: (A) pseudo-first-order, (B) pseudo-second-order, (C) intraparticle diffusion, and (D) Elovich.

where $C_{0}$ is the initial $\mathrm{Ag}$ concentration $(\mathrm{mg} / \mathrm{L})$, and $C_{\mathrm{e}}$ is the equilibrium $\mathrm{Ag}$ concentration $(\mathrm{mg} / \mathrm{L}), V$ is the volume of the $\mathrm{AgCNP}$ solution (L), and $m$ is the mass of the aged IOMPs $(\mathrm{g})$.

Desorption and Reuse of Aged IOMPs. The reuse of IOMPs as adsorbents was evaluated by testing the adsorbents over four adsorption-desorption cycles. For each adsorption cycle, $20 \mathrm{mg}$ of aged IOMPs was used per $100 \mathrm{~mL}$ of $1 \mathrm{mg} / \mathrm{L}$ AgCNP solution and the mixture were shaken at $300 \mathrm{rpm}$ for $20 \mathrm{~min}$. For desorption, the IOMPs were then shaken in $1 \mathrm{~mL}$ of an aqueous solution containing $10 \mathrm{mM}$ thiourea and $2 \% \mathrm{HAc}$ at $300 \mathrm{rpm}$ for $30 \mathrm{~min}$. The removal efficiency (Removal, \%) and recovery (Recovery, \%) were calculated by

$$
\operatorname{Removal}(\%)=\frac{C_{0}-C_{\mathrm{e}}}{C_{0}} \times 100
$$

and

$$
\text { Recovery }(\%)=\frac{C_{\mathrm{d}} V_{\mathrm{d}}}{C_{0} V_{0}} \times 100
$$

where $C_{0}$ is the initial $\mathrm{Ag}$ concentration $(\mathrm{mg} / \mathrm{L}), C_{\mathrm{e}}$ is the equilibrium $\mathrm{Ag}$ concentration $(\mathrm{mg} / \mathrm{L}), C_{\mathrm{d}}$ is the equilibrium $\mathrm{Ag}$ concentration of the desorption solution $(\mathrm{mg} / \mathrm{L}), V_{\mathrm{d}}$ is the volume of the desorption solution (L), and $V_{0}$ is the volume of the AgCNP solution (L).
Effect of Metal Oxide NPs on Removal of AgCNPs. Model dispersions of AgNPs, $\mathrm{ZnO} \mathrm{NPs}$, and $\mathrm{NiO} \mathrm{NPs}$ in real waters were prepared as follows: $0.5 \mathrm{~mL}$ of AgNPs $(20 \mathrm{mg} / \mathrm{L}), \mathrm{ZnO}$ NPs $(100 \mathrm{mg} /$ $\mathrm{L})$ and $\mathrm{NiO} \mathrm{NPs}(100 \mathrm{mg} / \mathrm{L})$ were spiked into $98.5 \mathrm{~mL}$ of lake water and wastewater treatment plant (WWTP) influent, and then shaken at $300 \mathrm{rpm}$ for $1 \mathrm{~h}$. The removal and desorption process then were performed following the above-mentioned procedures.

\section{RESULTS AND DISCUSSION}

Characterization of AgCNPs. As observed under TEM, the size distribution of all the studied AgCNPs were in the range of $2-48 \mathrm{~nm}$ in diameter (Figure S1 in the Supporting Information). The hydrodynamic size, polydispersity index (PDI), and the zeta potential values of the AgCNPs were determined by DLS (Table S2 in the Supporting Information). All NP samples had a polydispersity index (PDI) range of 0.167-0.387, indicating that the AgCNPs were well-dispersed. The zeta potentials of the AgCNPs indicated that all samples were negatively charged.

Characterization of IOMPs. According to our previous study, aging has little impact on the size and morphology. ${ }^{38}$ Here, the size and morphology of the aged IOMPs were investigated with TEM and SEM. Results showed that size 
Table 1. Adsorption Kinetic Parameters of Various Models for the Adsorption of AgCNPs by aged IOMPs

\begin{tabular}{|c|c|c|c|c|}
\hline \multirow[b]{2}{*}{ AgCNPs } & \multicolumn{4}{|c|}{ Pseudo-First-Order } \\
\hline & $Q_{e \exp }{ }^{a}(\mathrm{mg} / \mathrm{g})$ & $k_{1}\left(\times 10^{-3} \min ^{-1}\right)$ & $Q_{e, \text { cal }}^{b}(\mathrm{mg} / \mathrm{g})$ & $R^{2}$ \\
\hline AgNPs & 47.4 & 86.7 & 43.3 & 0.9856 \\
\hline $\mathrm{Ag} \& \mathrm{Ag}_{2} \mathrm{~S}$ NPs & 67.9 & 80.3 & 13.3 & 0.5472 \\
\hline $\mathrm{Ag}_{2} \mathrm{~S}$ NPs & 21.5 & 90.7 & 6.25 & 0.8473 \\
\hline $\mathrm{AgCl} \mathrm{NPs}$ & 42.2 & 65.5 & 6.73 & 0.6924 \\
\hline \multirow[b]{2}{*}{ AgCNPs } & \multicolumn{4}{|c|}{ Pseudo-Second-Order } \\
\hline & $Q_{\mathrm{e}, \exp }{ }^{a}(\mathrm{mg} / \mathrm{g})$ & $k_{2}\left(\times 10^{-3} \mathrm{~g} \mathrm{mg}^{-1} \min ^{-1}\right)$ & $Q_{e, \text { cal }}^{b}(\mathrm{mg} / \mathrm{g})$ & $R^{2}$ \\
\hline AgNPs & 47.4 & 3.15 & 51.5 & 0.9987 \\
\hline $\mathrm{Ag} \& \mathrm{Ag}_{2} \mathrm{~S}$ NPs & 67.9 & 12.0 & 68.5 & 0.9996 \\
\hline $\mathrm{Ag}_{2} \mathrm{~S}$ NPs & 21.5 & 71.5 & 21.3 & 0.9997 \\
\hline \multirow[t]{2}{*}{$\mathrm{AgCl} \mathrm{NPs}$} & 42.2 & 21.4 & 44.6 & 0.9999 \\
\hline & \multicolumn{4}{|c|}{ Intraparticle Diffusion } \\
\hline AgCNPs & $k_{\mathrm{p} 1}\left(\mathrm{mg} \mathrm{g}^{-1} \min ^{-0.5}\right)$ & $k_{\mathrm{p} 2}$ & $R^{2}$ & $k_{\mathrm{p} 3}\left(\mathrm{mg} \mathrm{g}^{-1} \min ^{-0.5}\right)$ \\
\hline AgNPs & 8.42 & 0.9852 & 0.9932 & 0.20 \\
\hline $\mathrm{Ag} \& \mathrm{Ag}_{2} \mathrm{~S}$ & 9.70 & 0.9925 & & \\
\hline $\mathrm{Ag}_{2} \mathrm{~S}$ NPs & 2.80 & 0.9411 & & \\
\hline $\mathrm{AgCl} \mathrm{NPs}$ & 4.77 & 0.9936 & & \\
\hline & & Elovich & & \\
\hline AgCNPs & $\alpha(\mathrm{mg}$ & & & $R^{2}$ \\
\hline AgNPs & & & & 0.9396 \\
\hline $\mathrm{Ag} \& \mathrm{Ag}_{2} \mathrm{~S}$ & & & & 0.8008 \\
\hline $\mathrm{Ag}_{2} \mathrm{~S}$ NPs & & & & 0.8043 \\
\hline $\mathrm{AgCl}$ NPs & & & & 0.7883 \\
\hline
\end{tabular}

${ }^{a}$ Experimental $Q_{e} ;{ }^{b}$ Calculated $Q_{e}$.

ranges from $150 \mathrm{~nm}$ to $330 \mathrm{~nm}$ in diameter, and that the aged IOMPs were well dispersed and had a rough surface (Figure 1). Furthermore, the structure of as-synthesized pristine and aged IOMPs was characterized by XRD (Figure 1C). Six characteristic peaks at $30.1^{\circ}, 35.4^{\circ}, 43.1^{\circ}, 53.4^{\circ}, 56.9^{\circ}$, and $62.5^{\circ}$, corresponding to planes (220), (311), (400), (422), (511), and (440) of magnetite (JCPDS File No. 19-0629), respectively, were observed for both pristine and aged IOMPs. This result revealed that the IOMPs are polycrystalline with a short-range mesoscopic ordering structure, and no phase change of $\mathrm{Fe}_{3} \mathrm{O}_{4}$ was observed, even though the IOMPs are aged.

Adsorption Kinetics. The solute uptake rate governs the equilibrium of the sorption reaction at the solid/solution interface. The AgCNP adsorption by the aged IOMPs was studied by determining the variation of the AgCNP concentration $(\mathrm{mg} / \mathrm{L})$ in aqueous phase at $\mathrm{pH} 6.2$ from 5 to $90 \mathrm{~min}$. A significant color fading with time was observed in the optical image of AgNP dispersion (Figure S2 in the Supporting Information). The AgCNP adsorption occurs rapidly during the first $15 \mathrm{~min}$ (Figure S3 in the Supporting Information), which may be ascribed to the abundant amount of available active sites on the aged IOMPs. Then, the active sites in the system gradually decreased and the adsorption equilibrium was reached.

To examine the adsorption mechanisms, the pseudo-firstorder model, pseudo-second-order model, and intraparticle diffusion model were used to analyze the adsorption data, respectively. The fitting precision between the experimental data and model-predicted value was evaluated with the correlation coefficient $R^{2}$.

The pseudo-first-order and pseudo-second-order models are linearly expressed as eqs 5 and 6 , respectively: ${ }^{44,45}$

$$
\begin{aligned}
& \ln \left(Q_{\mathrm{e}}-Q_{t}\right)=\ln Q_{\mathrm{e}}-k_{1} t \\
& \frac{t}{Q_{t}}=\frac{1}{k_{2} Q_{\mathrm{e}}{ }^{2}}+\frac{1}{Q_{\mathrm{e}}}
\end{aligned}
$$

where $Q_{e}(\mathrm{mg} / \mathrm{g})$ and $Q_{t}(\mathrm{mg} / \mathrm{g})$ are the respective amount of AgCNPs adsorbed per unit weight of aged IOMPs at equilibrium and at time $t(\mathrm{~min})$, and $k_{1}\left(\mathrm{~min}^{-1}\right)$ and $k_{2}(\mathrm{~g}$ $\mathrm{mg} \min ^{-1}$ ) are the respective rate constants for the pseudo-firstorder model and pseudo-second-order model. Figures $2 \mathrm{~A}$ and 2B showed the fitting of the experimental data to the two models, and the obtained kinetic parameters are shown in Table 1. The calculated $Q_{e}$ from the pseudo-second-order model agreed with the experimental value. In addition, significantly higher correlation coefficients were observed for the pseudo-second-order model (0.9987-0.9999) than the pseudo-first-order model (0.5472-0.9856). These results indicated that the adsorption of AgCNPs onto aged IOMPs agrees well to the pseudo-second-order model and the adsorption process may be controlled by intraparticle diffusion and weak interactions. ${ }^{46}$

Intraparticle diffusion model was used to interpret the movement of the species from the surface of the adsorbents to the inner pores. The model is linearly expressed as ${ }^{46}$

$$
Q_{t}=k_{\mathrm{d}} t^{1 / 2}+C
$$

where $k_{\mathrm{d}}\left(\mathrm{mg} \mathrm{g}^{-1} \mathrm{~min}^{-1 / 2}\right)$ is the intraparticle diffusion rate constant or rate factor, and $C(\mathrm{mg} / \mathrm{g})$ is the intraparticle diffusion rate constant, which is related to the boundary layer thickness. As shown in Figure 2C, the plots of $Q_{t}$ vs $t^{1 / 2}$ are nonlinear over the studied time range, indicating a multistage adsorption process. ${ }^{47,48}$ A close examination revealed the existence of three regions for the AgNPs. In stage I, the 

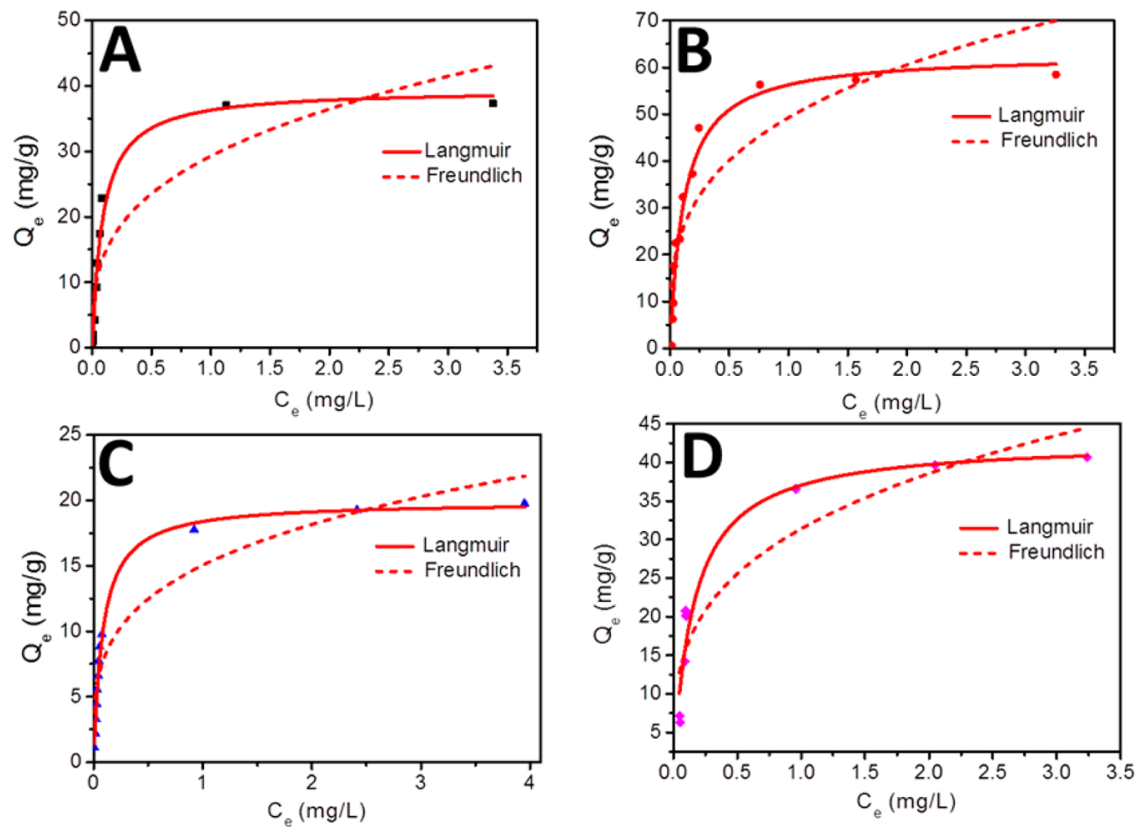

Figure 3. Adsorption isotherm for AgCNPs at room temperature: (A) AgNPs, (B) $\mathrm{Ag}_{2} \mathrm{Ag}_{2} \mathrm{~S} \mathrm{NPs},(\mathrm{C}) \mathrm{Ag}_{2} \mathrm{~S}$ NPs, and (D) $\mathrm{AgCl} \mathrm{NPs}$. Initial concentration of AgCNPs: $0.01-15 \mathrm{mg} / \mathrm{L}$.

external diffusion and adsorption was rapid at the surface. In stage II, a slow intraparticle diffusion occurs. Finally, in stage III, a much slower intraparticle diffusion occurs toward the final part of the adsorption process. However, only two regions were observed for the $\mathrm{Ag} \& \mathrm{Ag}_{2} \mathrm{~S}, \mathrm{Ag}_{2} \mathrm{~S}$ NPs, and $\mathrm{AgCl}$ NPs. The first stage is defined by rapid external diffusion and adsorption at the surface, and the second stage has a slow intraparticle diffusion that occurs toward the final part of the adsorption process.

The multistage adsorption process was further verified by the presence of three respective diffusion rate constants $k_{\mathrm{p} 1}, k_{\mathrm{p} 2}, k_{\mathrm{p} 3}$ for regions I, II, and III (Table 1). Among all of the AgCNPs, the maximum $k_{\mathrm{p} 1}$ value indicated that the AgCNPs transferred fastest from the aqueous solution to the aged IOMP surface. Interestingly, $k_{\mathrm{p} 1}$ for the $\mathrm{Ag} \& \mathrm{Ag}_{2} \mathrm{~S}$ NPs was higher than that for the AgNPs, suggesting the sulfidation of AgNPs increases the intraparticle diffusion rate, and then results in a positive effect on AgCNP adsorption. This can be due to the reduction of stability caused by the change in physicochemical properties, such as the zeta potential (Table S2 in the Supporting Information).

The Elovich equation is typically used to describe the kinetics of chemisorption on highly heterogeneous sorbents, which can be linearly expressed as ${ }^{49}$

$$
Q_{t}=\frac{\ln (\alpha \beta)}{\beta}+\frac{\ln t}{\beta}
$$

where $Q_{t}(\mathrm{mg} / \mathrm{g})$ is the adsorption capacity for the AgCNPs at time $t, \alpha\left(\mathrm{mg} \mathrm{g}^{-1} \mathrm{~min}^{-1}\right)$ is the initial adsorption rate, and $\beta$ $\left(\mathrm{mg} \mathrm{g} \mathrm{g}^{-1} \min ^{-1}\right)$ is the desorption rate. A weak linear relationship between $Q_{t}$ and $\ln t$ was observed for all of the AgCNPs (Figure 2D). In addition, the values for the $\alpha$ calculated from the slope deviate significantly with the experimental $Q_{e}$ (shown in Table 1 ), especially for $\mathrm{Ag}_{2} \mathrm{~S}$ NPs $\left(1.09 \times 10^{5} \mathrm{mg} \mathrm{g}^{-1} \mathrm{~min}^{-1}\right)$ and $\mathrm{AgCl} \mathrm{NPs}\left(3.13 \times 10^{4} \mathrm{mg} \mathrm{g}^{-1}\right.$ $\left.\mathrm{min}^{-1}\right)$. These results suggested that the adsorption processes are not controlled by chemisorption.
Adsorption Isotherms. Adsorption isotherms and the equilibrium adsorption capacity $\left(Q_{e}\right)$, as a function of equilibrium concentration $\left(C_{\mathrm{e}}\right)$ at constant temperature, were studied. The parameters obtained from the different models reflect the surface characteristics of the adsorbents. The equilibrium data were fit with the Langmuir, Freundlich, and Dubinin-Radushkevich isotherm models, respectively. Figure 3 presents the Langmuir and Freundlich plots for the removal of various AgCNPs at room temperature.

The Langmuir model assumes that the adsorption occurs at specific homogeneous sites on the adsorbents, and has been successfully applied in monolayer adsorption process. The equation can be linearly expressed as ${ }^{50}$

$$
\frac{C_{e}}{Q_{e}}=\frac{C_{e}}{Q_{m}}+\frac{1}{Q_{m} K_{L}}
$$

where $C_{\mathrm{e}}(\mathrm{mg} / \mathrm{L})$ is the equilibrium $\mathrm{AgCNP}$ concentration in the water sample, $Q_{e}$ the equilibrium adsorption capacity of the AgCNPs, $Q_{m}(\mathrm{mg} / \mathrm{g})$ the maximum adsorption capacity for the AgCNPs, and $K_{\mathrm{L}}\left(\mathrm{L} \mathrm{mg}^{-1}\right)$ the Langmuir isotherm constant. The maximum adsorption capacities of the aged IOMPs for different AgCNPs are shown in Table 2.

In addition, a nondimensional constant $\left(R_{\mathrm{L}}\right)$, known as the equilibrium parameter, was used to predict the type of adsorption process, and is expressed as ${ }^{50}$

$$
R_{\mathrm{L}}=\frac{1}{1+K_{\mathrm{L}} C_{0}}
$$

where $C_{0}$ is the initial AgCNP concentration $(\mathrm{mg} / \mathrm{L})$. When the isotherm is linear or irreversible, $R_{\mathrm{L}}$ is 1 or 0 , respectively. Furthermore, the isotherm is favorable when $0<R_{\mathrm{L}}<1$ and unfavorable when $R_{\mathrm{L}}>1$. The parameters derived from the Langmuir isotherm are shown in Table 2.

The Freundlich isotherm assumes a heterogeneous adsorption of pollutants onto the adsorbent, and the equation is expressed as ${ }^{51}$ 
Table 2. Langmuir, Freundlich, and Dubinin-Radushkevich Parameters for Various AgCNP Adsorption by Aged IOMPs

\begin{tabular}{|c|c|c|c|c|c|}
\hline \multirow[b]{2}{*}{ AgCNPs } & \multicolumn{5}{|c|}{ Langmuir } \\
\hline & $Q_{\mathrm{m}}(\mathrm{mg} / \mathrm{g})$ & $b(\mathrm{~L} / \mathrm{mg})$ & & $R_{\mathrm{L}}$ & $R^{2}$ \\
\hline AgNPs & 39.5 & 11.3 & & $55-0.8831$ & 0.9789 \\
\hline $\mathrm{Ag} \& \mathrm{Ag}_{2} \mathrm{~S}$ NPs & 62.9 & 8.53 & & $48-0.6311$ & 0.9650 \\
\hline $\mathrm{Ag}_{2} \mathrm{~S}$ NPs & 19.9 & 12.0 & & $52-0.8776$ & 0.9923 \\
\hline \multirow[t]{2}{*}{$\mathrm{AgCl} \mathrm{NPs}$} & 42.8 & 6.41 & & 779-0.0509 & 0.9477 \\
\hline & \multicolumn{5}{|c|}{ Freundlich Equation } \\
\hline AgCNPs & \multicolumn{3}{|c|}{$K_{\mathrm{F}}\left(\mathrm{mg}^{1-(1 / n)} \mathrm{L}^{1 / n} \mathrm{~g}^{-1}\right)$} & $n$ & $R^{2}$ \\
\hline AgNPs & \multicolumn{3}{|c|}{3.16} & 29.3 & 0.8429 \\
\hline $\mathrm{Ag} \& \mathrm{Ag}_{2} \mathrm{~S}$ NPs & \multicolumn{3}{|c|}{3.46} & 49.3 & 0.7876 \\
\hline $\mathrm{Ag}_{2} \mathrm{~S}$ NPs & \multicolumn{3}{|c|}{3.68} & 15.0 & 0.9004 \\
\hline $\mathrm{AgCl} \mathrm{NPs}$ & \multicolumn{3}{|c|}{3.37} & 31.4 & 0.8580 \\
\hline \multirow[b]{2}{*}{ AgCNPs } & \multicolumn{5}{|c|}{ Dubinin-Radushkevich Equation } \\
\hline & \multicolumn{3}{|c|}{$\beta\left(\mathrm{mol}^{2} \mathrm{~kJ}^{-2}\right)$} & $R^{2}$ & $E(\mathrm{~kJ} / \mathrm{mol})$ \\
\hline AgNPs & \multicolumn{3}{|c|}{$23.9 \times 10^{-3}$} & 0.9762 & 4.57 \\
\hline${\mathrm{Ag} \& \mathrm{Ag}_{2} \mathrm{~S} \text { NPs }}$ & \multicolumn{3}{|c|}{$18.7 \times 10^{-3}$} & 0.9596 & 5.17 \\
\hline $\mathrm{Ag}_{2} \mathrm{~S}$ NPs & \multicolumn{3}{|c|}{$22.5 \times 10^{-3}$} & 0.9838 & 4.71 \\
\hline $\mathrm{AgCl} \mathrm{NPs}$ & \multicolumn{3}{|c|}{$29.9 \times 10^{-3}$} & 0.9199 & 4.09 \\
\hline
\end{tabular}

$$
\ln Q_{\mathrm{e}}=\ln K_{\mathrm{F}}+\frac{\ln C_{\mathrm{e}}}{n}
$$

where $Q_{e}$ is the equilibrium adsorption capacity of the AgCNPs $(\mathrm{mg} / \mathrm{L})$, and $K_{\mathrm{F}}\left(\mathrm{mg}^{1-(1 / n)} \mathrm{L}^{1 / n} \mathrm{~g}^{-1}\right)$ is the Freundlich constant, which is related to the adsorption capacity. $n$ is the adsorption intensity, representing the favorability of adsorption, where $n<$ 1 shows that a favorable adsorption occurs in the concentration range studied, and $n>1$ suggests the adsorption is favorable at only high concentrations. The parameters derived from the Freundlich isotherm are shown in Table 2.

According to the correlation parameters $\left(R^{2}\right)$ of these two models, the Langmuir isotherm model better describes the adsorption mechanism than the Freundlich isotherm model. $R_{\mathrm{L}}$ values (Table 2) indicate that favorable adsorption occurs between the aged IOMPs and various AgCNPs. In addition, analysis of the Langmuir $Q_{m}$ values of the AgNPs $(39.5 \mathrm{mg} / \mathrm{g}$ ) and $\mathrm{Ag} \& \mathrm{Ag}_{2} \mathrm{~S}$ NPs $(62.9 \mathrm{mg} / \mathrm{g})$ shows that the maximum adsorption capacity can be greatly improved by transforming the AgNPs into $\mathrm{Ag}_{2} \mathrm{~S}$ NPs. It is noteworthy that the physicochemical properties of NPs are dependent on the size and surface coating. Therefore, the maximum adsorption capacities are different for AgCNPs with the same chemical composition but different dimensions and coatings. ${ }^{34,52}$ As shown in Figure 4, a marked increase in the adsorption capacity was observed for both citrate-coated and PVP-coated AgNPs with sizes in the range of $10-60 \mathrm{~nm}$. Meanwhile, it was found that the adsorption capacities for citrate-coated AgNPs were normally higher than those for PVP-coated AgNPs with similar sizes, which is mainly due to the higher negative surface charges of citrate-coated AgNPs (Table $\mathrm{S} 1$ in the Supporting Information).

The sorption data was further analyzed using a DubininRadushkevich isotherm model to distinguish between physical and chemical adsorption of the AgCNPs. The equation can be expressed as ${ }^{53}$

$$
\ln Q_{\mathrm{e}}=\ln Q_{\mathrm{m}}-\beta \varepsilon^{2}
$$

where $Q_{e}$ is the equilibrium adsorption capacity $\left(\mathrm{mol} \mathrm{g}^{-1}\right), Q_{m}$ is the maximum adsorption capacity $\left(\mathrm{mol} \mathrm{g}^{-1}\right), \beta$ is an activity

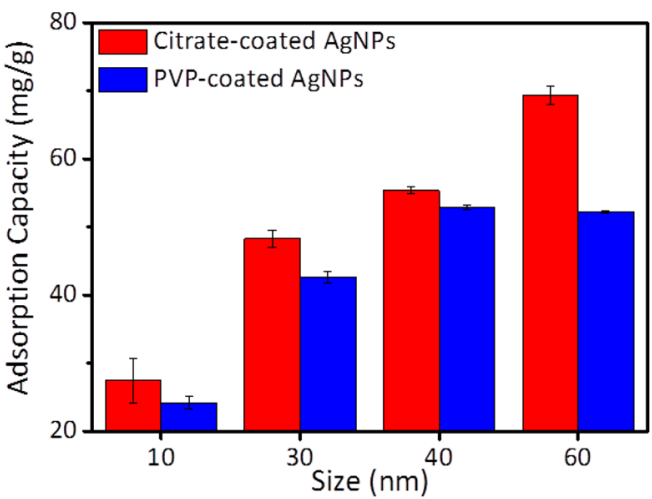

Figure 4. Effect of NP sizes and coatings on the adsorption capacities of the aged IOMPs for AgNPs. Initial concentration of AgNPs: $\sim 15$ $\mathrm{mg} / \mathrm{L}$.

coefficient related to the mean free energy of adsorption $\left(\mathrm{mol}^{2}\right.$ $\mathrm{kJ}^{-2}$ ), and $\varepsilon$ is the Polanyi potential, which is expressed as ${ }^{53}$

$$
\varepsilon=\mathrm{R} T\left(1+\frac{1}{C_{\mathrm{e}}}\right)
$$

where $\mathrm{R}$ is the gas constant $\left(\mathrm{R}=8.314 \mathrm{~J} \mathrm{~mol}^{-1} \mathrm{~K}^{-1}\right)$ and $T$ is the temperature $(\mathrm{K}) . C_{\mathrm{e}}(\mathrm{mg} / \mathrm{L})$ is the equilibrium $\mathrm{AgCNP}$ concentration in the water sample.

By plotting $\ln Q_{e}$ against $\varepsilon^{2}$, the equilibrium data fit the Dubinin-Radushkevich isotherm model well. $Q_{\mathrm{m}}$ and $\beta$ can be calculated using the intercept and slope of the fit. The mean free energy of adsorption is described as ${ }^{53}$

$$
E=\frac{1}{\sqrt{2 \beta}}
$$

The process is chemical adsorption when $8 \mathrm{~kJ} / \mathrm{mol}<E<16$ $\mathrm{kJ} / \mathrm{mol}$, and physical adsorption dominates when $E<8 \mathrm{~kJ} /$ mol. $^{54}$ The parameters derived from the Dubinin-Radushkevich equation and $E$ are shown in Table 2. The values of $E$ $(4.09-5.17 \mathrm{~kJ} / \mathrm{mol})$ indicate that the adsorption of AgCNPs by aged IOMPs is a physisorption process. This agrees well with that obtained in our previous study, where electrostatic interactions between positively charged aged IOMPs and negatively charged AgCNPs at $\mathrm{pH} 6.2$ play key roles in the extraction of AgCNPs. ${ }^{38}$

Desorption and Reuse of Aged IOMPs. Cost should be taken into consideration for new adsorbents used in water treatment. To this end, the reusability of the aged IOMPs was evaluated by subjecting the adsorbents to four consecutive adsorption-desorption processes. The desorption of the AgCNPs from the aged IOMPs were performed in $10 \mathrm{mM}$ thiourea in $2 \%(\mathrm{v} / \mathrm{v}) \mathrm{HAc}$, followed by shaking at $300 \mathrm{rpm}$ for $30 \mathrm{~min}$, which is a procedure that was verified in our previous study. ${ }^{38}$ Figure 5 indicates that the aged IOMPs exhibited excellent performances of adsorption and desorption throughout the cycles tested, while the recoveries of the AgCNPs decreased by $<16.9 \%$, compared to the first cycle, indicating that the aged IOMPs are stable during the desorption and the materials can be reused.

Effect of Metal Oxide NPs on Removal of AgCNPs. Considering the great diversity of particles in the industrial nanowastes and real environmental waters, potential interferences from other particles in the removal of AgNPs were studied. Metal oxide NPs (MO NPs) as another widely 

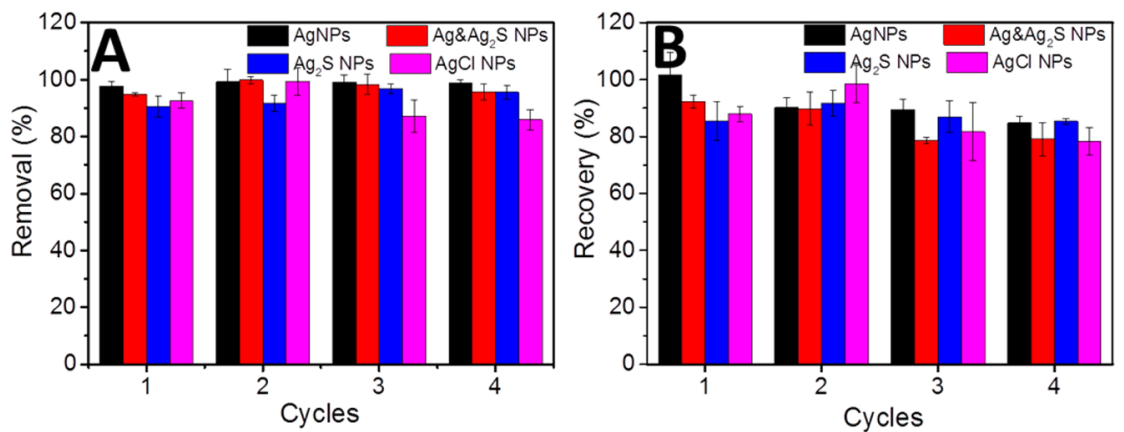

Figure 5. (A) Removal and (B) recovery amounts of AgCNPs over four adsorption-desorption cycles. Initial concentration of AgCNPs: $1 \mathrm{mg} / \mathrm{L}$.
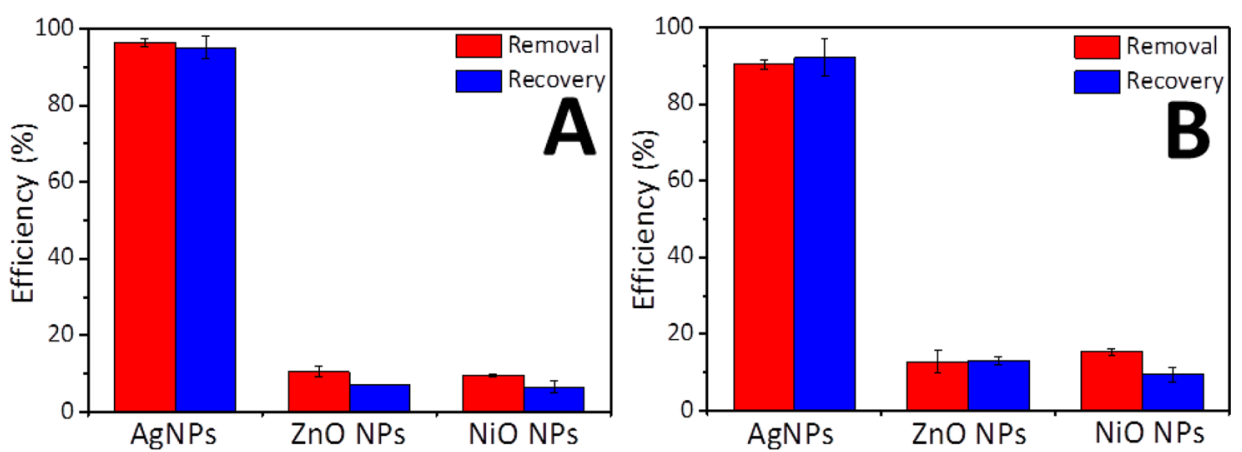

Figure 6. Removal and recovery of AgNPs, ZnO NPs and NiO NPs in real waters spiked with a mixture of $100 \mu \mathrm{g} / \mathrm{L} \mathrm{AgNPs,} 500 \mu \mathrm{g} / \mathrm{L} \mathrm{ZnO} \mathrm{NPs}$, and $500 \mu \mathrm{g} / \mathrm{L} \mathrm{NiO} \mathrm{NPs:} \mathrm{(A)} \mathrm{lake} \mathrm{water} \mathrm{and} \mathrm{(B)} \mathrm{wastewater} \mathrm{treatment} \mathrm{plant} \mathrm{(WWTP)} \mathrm{influent.}$

produced NPs, whose isoelectric points (IEPs) were $>7.1$, $^{55}$ were exemplarily selected. Here, $\mathrm{ZnO} \mathrm{NPs}$ and $\mathrm{NiO}$ NPs were used as models. As shown in Figure 6, the removal and recovery efficiencies in lake water and WWTP influent spiked with a 1:5:5 mixture of $\mathrm{Ag} / \mathrm{ZnO} / \mathrm{NiO} \mathrm{NPs}$ were $>90.4 \%$ and $>92.3 \%$ for AgNPs, respectively, while $<15.4 \%$ of $\mathrm{ZnO} \mathrm{NPs}$ and $\mathrm{NiO}$ NPs were removed. These results indicated the promise specificity of the aged IOMPs as adsorbents for AgCNPs, even in the WWTP influent with complex matrixes, which is essential for the practical application in removal of AgCNPs from the nanowastes and real environmental waters.

Comparison with Other Adsorbents. As shown in Table 3 , the maximum adsorption capacities of the aged IOMPs are comparable to that of other adsorbents for the removal of

Table 3. Comparison of the Removal of AgCNP by IOMPs with Other Absorbents

\begin{tabular}{|c|c|c|c|c|}
\hline adsorbents & $\mathrm{AgCNPs}$ & $\begin{array}{l}\text { maximum } \\
\text { adsorption } \\
\text { capacity } \\
(\mathrm{mg} / \mathrm{g})\end{array}$ & $\begin{array}{l}\text { adsorption } \\
\text { equilibrium } \\
\text { time }\end{array}$ & ref \\
\hline $\begin{array}{l}\text { surface-modified } \\
\text { electrospun } \\
\text { PVA nanofibers }\end{array}$ & AgNPs & $23.8-55.8$ & $3 \mathrm{~h}$ & 30 \\
\hline $\begin{array}{l}\text { cellulose-based } \\
\text { nanofibers }\end{array}$ & AgNPs & 13.1 & $6 \mathrm{~h}$ & 31 \\
\hline $\begin{array}{l}\text { PVA/gluten } \\
\text { nanofibers }\end{array}$ & AgNPs & 31.84 & $2 \mathrm{~h}$ & 33 \\
\hline $\begin{array}{l}\text { biomimetic metal } \\
\text { oxides }\end{array}$ & AgNPs & $5.0-54.8$ & $3 \mathrm{~h}$ & 34 \\
\hline $\begin{array}{l}\text { plasma-treated } \\
\text { nanofiber } \\
\text { membranes }\end{array}$ & AgNPs & 38.62 & $3 \mathrm{~h}$ & 56 \\
\hline aged IOMPs & $\begin{array}{l}\text { AgNPs, }{\mathrm{Ag} \& \mathrm{Ag}_{2} \mathrm{~S}} \mathrm{NPs}, \mathrm{Ag}_{2} \mathrm{~S} \mathrm{NPs} \\
\text { and } \mathrm{AgCl} \text { NPs }\end{array}$ & $19.9-62.8$ & $20 \mathrm{~min}$ & $\begin{array}{l}\text { this } \\
\text { study }\end{array}$ \\
\hline
\end{tabular}

AgNPs from environmental waters. However, the adsorption time is much less $(<20 \mathrm{~min})$ than those reported previously. Furthermore, the aged IOMPs are also effective for the removal of other AgCNPs, such as $\mathrm{Ag} \& \mathrm{Ag}_{2} \mathrm{~S}$ NPs, $\mathrm{Ag}_{2} \mathrm{~S} \mathrm{NPs}$, and $\mathrm{AgCl}$ NPs.

Effect of Real Water Matrix. To evaluate the practical use of aged IOMPs, five real environmental waters spiked with 10 $\mu \mathrm{g} / \mathrm{L}$ each of the studied AgCNPs were subjected to the typical NP removal and recovery process. The characterization information for the waters are shown in Table S3 in the Supporting Information, all the samples were weakly alkaline ( $\mathrm{pH}$ 7.94-8.49), and contained a considerable concentration of common cations $\left(4.6-135.1 \mathrm{mg} / \mathrm{L} \mathrm{Na}^{+}, \mathrm{Mg}^{2+}, \mathrm{K}^{+}\right.$, and $\mathrm{Ca}^{2+}$ ) and DOM (5.3-46.8 $\mathrm{mg} \mathrm{C} / \mathrm{L})$. The removal efficiencies and recoveries of the water samples were in the range of $63.3 \%-$ 99.9\% and $67.1 \%-99.9 \%$ (Table S4), respectively, indicating that the matrix has limited influence on the removal of AgCNPs, and therefore the aged IOMPs could be utilized for the removal of AgCNPs from real waters. Note that, although AgCNPs could be removed in a conventional wastewater treatment process, ${ }^{57}$ most of them entered the activated sludge, resulting in secondary environmental pollution. ${ }^{23}$ Since the precious metal $\mathrm{Ag}$ is horribly difficult to recover, further processing is often needed to recycle $\mathrm{Ag}$ in wastewater treatment processes.

In conclusion, aged IOMPs were shown to be promising adsorbents for the removal and recovery of various AgCNPs

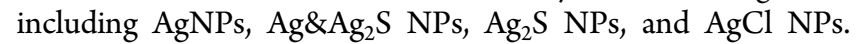
The adsorption kinetics and adsorption isotherm of AgCNPs on aged IOMPs fit well to the presudo-second-order kinetic model and Langmuir isotherm model, respectively. The agreement to Dubinin-Radushkevich model verified that the AgCNPs were physisorbed onto the aged IOMPs. In comparison to other adsorbents in literatures, IOMPs showed 
much shorter adsorption equilibrium time and comparable maximum adsorption capacities. Moreover, the removal and recovery of the AgCNPs remained nearly unchanged after four adsorption-desorption cycles, and the aged IOMPs could remove $63.3 \%-99.9 \%$ of the AgCNPs from real water samples, demonstrating the applicability of aged IOMPs as renewable and efficient adsorbents for the removal of AgCNPs from polluted waters.

\section{ASSOCIATED CONTENT}

\section{S Supporting Information}

The Supporting Information is available free of charge on the ACS Publications website at DOI: 10.1021/acssuschemeng.7b00797.

Details about synthesis of NPs, water collection and additional references (Figure S1-S3 and Tables S1-S3) (PDF)

\section{AUTHOR INFORMATION}

\section{Corresponding Author}

*Tel.: +86-10-62849192. Fax: +86-10-62849192. E-mail: jfliu@ rcees.ac.cn.

\section{ORCID}

Jing-fu Liu: 0000-0001-7134-7026

\section{Notes}

The authors declare no competing financial interest.

\section{ACKNOWLEDGMENTS}

This work was supported by the National Key Research and Development Program of China (No. 2016YFA0203102), the Strategic Priority Research Program of the Chinese Academy of Sciences (No. XDB14020101), and the National Natural Science Foundation of China (Nos. 21337004, 21507145).

\section{REFERENCES}

(1) Alivisatos, P. The use of nanocrystals in biological detection. Nat. Biotechnol. 2004, 22, 47-52.

(2) Tolaymat, T. M.; El Badawy, A. M.; Genaidy, A.; Scheckel, K. G.; Luxton, T. P.; Suidan, M. An evidence-based environmental perspective of manufactured silver nanoparticle in syntheses and applications: A systematic review and critical appraisal of peerreviewed scientific papers. Sci. Total Environ. 2010, 408, 999-1006.

(3) Chaloupka, K.; Malam, Y.; Seifalian, A. M. Nanosilver as a new generation of nanoproduct in biomedical applications. Trends Biotechnol. 2010, 28, 580-588.

(4) Dror-Ehre, A.; Adin, A.; Markovich, G.; Mamane, H. Control of biofilm formation in water using molecularly capped silver nanoparticles. Water Res. 2010, 44, 2601-2609.

(5) Quadros, M. E.; Marr, L. C. Silver nanoparticles and total aerosols emitted by nanotechnology-related consumer spray products. Environ. Sci. Technol. 2011, 45, 10713-10719.

(6) Quadros, M. E.; Pierson, R.; Tulve, N. S.; Willis, R.; Rogers, K.; Thomas, T. A.; Marr, L. C. Release of silver from nanotechnologybased consumer products for children. Environ. Sci. Technol. 2013, 47, 8894-8901.

(7) Pettibone, J. M.; Liu, J. In situ methods for monitoring silver nanoparticle sulfidation in simulated waters. Environ. Sci. Technol. 2016, 50, 11145-11153.

(8) Levard, C.; Hotze, E. M.; Lowry, G. V.; Brown, G. E., Jr. Environmental transformations of silver nanoparticles: Impact on stability and toxicity. Environ. Sci. Technol. 2012, 46, 6900-6914.

(9) Khaksar, M.; Jolley, D. F.; Sekine, R.; Vasilev, K.; Johannessen, B.; Donner, E.; Lombi, E. In situ chemical transformations of silver nanoparticles along the water-sediment continuum. Environ. Sci. Technol. 2015, 49, 318-325.

(10) Leonardo, T.; Farhi, E.; Pouget, S.; Motellier, S.; Boisson, A.-M.; Banerjee, D.; Rébeillé, F.; den Auwer, C.; Rivasseau, C. Silver accumulation in the green microalga coccomyxa actinabiotis: Toxicity, in situ speciation, and localization investigated using synchrotron XAS, XRD, and TEM. Environ. Sci. Technol. 2016, 50, 359-367.

(11) Choi, O.; Deng, K. K.; Kim, N.-J.; Ross, L., Jr.; Surampalli, R. Y.; $\mathrm{Hu}, \mathrm{Z}$. The inhibitory effects of silver nanoparticles, silver ions, and silver chloride colloids on microbial growth. Water Res. 2008, 42, 3066-3074.

(12) Dror-Ehre, A.; Mamane, H.; Belenkova, T.; Markovich, G.; Adin, A. Silver nanoparticle-E. coli colloidal interaction in water and effect on E. coli survival. J. Colloid Interface Sci. 2009, 339, 521-526.

(13) Shen, M. H.; Zhou, X. X.; Yang, X. Y.; Chao, J. B.; Liu, R.; Liu, J. F. Exposure medium: Key in identifying free $\mathrm{Ag}^{+}$as the exclusive species of silver nanoparticles with acute toxicity to Daphnia magna. Sci. Rep. 2015, 5, 9674.

(14) Navarro, E.; Baun, A.; Behra, R.; Hartmann, N. B.; Filser, J.; Miao, A. J.; Quigg, A.; Santschi, P. H.; Sigg, L. Environmental behavior and ecotoxicity of engineered nanoparticles to algae, plants, and fungi. Ecotoxicology 2008, 17, 372-386.

(15) Jiang, H. S.; Li, M.; Chang, F. Y.; Li, W.; Yin, L. Y. Physiological analysis of silver nanoparticles and $\mathrm{AgNO}_{3}$ toxicity to Spirodela polyrhiza. Environ. Toxicol. Chem. 2012, 31, 1880-1886.

(16) Jiang, H. S.; Qiu, X. N.; Li, G. B.; Li, W.; Yin, L. Y. Silver nanoparticles induced accumulation of reactive oxygen species and alteration of antioxidant systems in the aquatic plant Spirodela polyrhiza. Environ. Toxicol. Chem. 2014, 33, 1398-1405.

(17) Osborne, O. J.; Lin, S.; Chang, C. H.; Ji, Z.; Yu, X.; Wang, X.; Lin, S.; Xia, T.; Nel, A. E. Organ-specific and size-dependent Ag nanoparticle toxicity in gills and intestines of adult zebrafish. ACS Nano 2015, 9, 9573-9584.

(18) AshaRani, P. V.; Mun, G. L. K.; Hande, M. P.; Valiyaveettil, S. Cytotoxicity and genotoxicity of silver nanoparticles in human cells. ACS Nano 2009, 3, 279-290.

(19) Ahamed, M.; AlSalhi, M. S.; Siddiqui, M. K. J. Silver nanoparticle applications and human health. Clin. Chim. Acta 2010, $411,1841-1848$.

(20) Rico, C. M.; Majumdar, S.; Duarte-Gardea, M.; Peralta-Videa, J. R.; Gardea-Torresdey, J. L. Interaction of nanoparticles with edible plants and their possible implications in the food chain. J. Agric. Food Chem. 2011, 59, 3485-3498.

(21) Yoo-iam, M.; Chaichana, R.; Satapanajaru, T. Toxicity, bioaccumulation and biomagnification of silver nanoparticles in green algae (Chlorella sp.), water flea (Moina macrocopa), blood worm (Chironomus spp.) and silver barb (Barbonymus gonionotus). Chem. Speciation Bioavailability 2014, 26, 257-265.

(22) Ribeiro, F.; Van Gestel, C. A. M.; Pavlaki, M. D.; Azevedo, S.; Soares, A. M. V. M; Loureiro, S. Bioaccumulation of silver in Daphnia magna: Waterborne and dietary exposure to nanoparticles and dissolved silver. Sci. Total Environ. 2017, 574, 1633-1639.

(23) Nowack, B.; Ranville, J. F.; Diamond, S.; Gallego-Urrea, J. A.; Metcalfe, C.; Rose, J.; Horne, N.; Koelmans, A. A.; Klaine, S. J. Potential scenarios for nanomaterial release and subsequent alteration in the environment. Environ. Toxicol. Chem. 2012, 31, 50-59.

(24) Yin, Y.; Tan, Z.; Hu, L.; Yu, S.; Liu, J.; Jiang, G. Isotope tracers to study the environmental fate and bioaccumulation of metalcontaining engineered nanoparticles: Techniques and applications. Chem. Rev. 2017, 117, 4462-4487.

(25) Chang, M. R.; Lee, D. J.; Lai, J. Y. Nanoparticles in wastewater from a science-based industrial park-Coagulation using polyaluminum chloride. J. Environ. Manage. 2007, 85, 1009-1014.

(26) Lin, Y. T.; Sung, M.; Sanders, P. F.; Marinucci, A.; Huang, C. P. Separation of nano-sized colloidal particles using cross-flow electrofiltration. Sep. Purif. Technol. 2007, 58, 138-147.

(27) Springer, F.; Laborie, S.; Guigui, C. Removal of $\mathrm{SiO}_{2}$ nanoparticles from industry wastewaters and subsurface waters by 
ultrafiltration: Investigation of process efficiency, deposit properties and fouling mechanism. Sep. Purif. Technol. 2013, 108, 6-14.

(28) Ganesh, R.; Smeraldi, J.; Hosseini, T.; Khatib, L.; Olson, B. H.; Rosso, D. Evaluation of nanocopper removal and toxicity in municipal wastewaters. Environ. Sci. Technol. 2010, 44, 7808-7813.

(29) Liu, J.; Sun, J.; Jiang, G. Use of cloud point extraction for removal of nanosized copper oxide from wastewater. Chin. Sci. Bull. 2010, 55, 346-349.

(30) Mahanta, N.; Valiyaveettil, S. Surface modified electrospun poly(vinyl alcohol) membranes for extracting nanoparticles from water. Nanoscale 2011, 3, 4625-4631.

(31) Mahanta, N.; Leong, W. Y.; Valiyaveettil, S. Isolation and characterization of cellulose-based nanofibers for nanoparticle extraction from an aqueous environment. J. Mater. Chem. 2012, 22, 1985-1993.

(32) Kumar, J.; Mallampati, R.; Adin, A.; Valiyaveettil, S. Functionalized carbon spheres for extraction of nanoparticles and catalyst support in water. ACS Sustainable Chem. Eng. 2014, 2, 2675-2682.

(33) Dhandayuthapani, B.; Mallampati, R.; Sriramulu, D.; Dsouza, R. F.; Valiyaveettil, S. PVA/Gluten hybrid nanofibers for removal of nanoparticles from water. ACS Sustainable Chem. Eng. 2014, 2, 10141021.

(34) Mallampati, R; Valiyaveettil, S. Biomimetic metal oxides for the extraction of nanoparticles from water. Nanoscale 2013, 5, 3395-3399.

(35) Zhao, Y.; Chen, H.; Li, J.; Chen, C. Hierarchical MWCNTs/ $\mathrm{Fe}_{3} \mathrm{O}_{4} /$ PANI magnetic composite as adsorbent for methyl orange removal. J. Colloid Interface Sci. 2015, 450, 189-195.

(36) Liu, J. F.; Zhao, Z. S.; Jiang, G. B. Coating $\mathrm{Fe}_{3} \mathrm{O}_{4}$ magnetic nanoparticles with humic acid for high efficient removal of heavy metals in water. Environ. Sci. Technol. 2008, 42, 6949-6954.

(37) Mahmoudi, M.; Sant, S.; Wang, B.; Laurent, S.; Sen, T. Superparamagnetic iron oxide nanoparticles (SPIONs): Development, surface modification and applications in chemotherapy. Adv. Drug Delivery Rev. 2011, 63, 24-46.

(38) Zhou, X.; Liu, J.; Yuan, C.; Chen, Y. Speciation analysis of silver sulfide nanoparticles in environmental waters by magnetic solid-phase extraction coupled with ICP-MS. J. Anal. At. Spectrom. 2016, 31, 2285-2292.

(39) Deng, Y.; Qi, D.; Deng, C.; Zhang, X.; Zhao, D. Superparamagnetic high-magnetization microspheres with an $\mathrm{Fe}_{3} \mathrm{O}_{4} @ \mathrm{SiO}_{2}$ core and perpendicularly aligned mesoporous $\mathrm{SiO}_{2}$ shell for removal of microcystins. J. Am. Chem. Soc. 2008, 130, 28-29.

(40) Pang, L.; Liu, J. Use of $\mathrm{Fe}_{3} \mathrm{O}_{4} @ n \mathrm{SiO}_{2} @ m \mathrm{SiO}_{2}$ magnetic mesoporous microspheres for fast determination of the sorption coefficients of polycyclic aromatic hydrocarbons to bovine serum albumin in aqueous phase. Huaxue Xuebao 2013, 71, 339-342.

(41) Al-Hazmi, F. S.; Al-Harbi, G. H.; Beall, G. W.; Al-Ghamdi, A. A.; Obaid, A. Y.; Mahmoud, W. E. Synthesis and structure of high quality graphene prepared via solvothermal exfoliation of intercalated graphite flakes. Superlattices Microstruct. 2015, 86, 270-274.

(42) Jiang, Z.; Zhu, C.; Wan, W.; Qian, K.; Xie, J. Constructing graphite-like carbon nitride modified hierarchical yolk-shell $\mathrm{TiO}_{2}$ spheres for water pollution treatment and hydrogen production. $J$. Mater. Chem. A 2016, 4, 1806-1818.

(43) Yan, H.; Yang, L.; Yang, Z.; Yang, H.; Li, A.; Cheng, R. Preparation of chitosan/poly(acrylic acid) magnetic composite microspheres and applications in the removal of copper(II) ions from aqueous solutions. J. Hazard. Mater. 2012, 229-230, 371-380.

(44) Lagergren, S. About the theory of so-called adsorption of soluble substances. K. Sven. Vetenskapsakad. Handl. 1898, 24, 1-39.

(45) Ho, Y. S.; McKay, G. Pseudo-second order model for sorption processes. Process Biochem. 1999, 34, 451-465.

(46) Srivastava, S. K.; Tyagi, R.; Pant, N. Adsorption of heavy-metal ions on carbonaceous materials developed from the waste supply generated in local fertilizer plants. Water Res. 1989, 23, 1161-1165.

(47) Medina, R. P.; Nadres, E. T.; Ballesteros, F. C., Jr.; Rodrigues, D. F. Incorporation of graphene oxide into a chitosan-poly(acrylic acid) porous polymer nanocomposite for enhanced lead adsorption. Environ. Sci.: Nano 2016, 3, 638-646.
(48) Ciobanu, G.; Barna, S.; Harja, M. Kinetic and equilibrium studies on adsorption of reactive blue 19 dye from aqueous solutions by nanohydroxyapatite adsorbent. Arch. Environ. Prot. 2016, 42, 3-11.

(49) Chien, S. H.; Clayton, W. R.; McClellan, G. H. Kinetics of dissolution phosphate rocks in soils. Soil Sci. Soc.Am. J. 1980, 44, 260264.

(50) Langmuir, I. The adsorption of gases on plane surface of glass, mica and platinum. J. Am. Chem. Soc. 1918, 40, 1361-1403.

(51) Freundlich, H. Concerning adsorption in solutions. Z. Phys. Chem., Stoechiom. Verwandtschaftsl. 1906, 57, 385-470.

(52) Padil, V. V. T.; Cernik, M. Poly(vinyl alcohol)/gum karaya electrospun plasma treated membrane for the removal of nanoparticles ( $\mathrm{Au}, \mathrm{Ag}, \mathrm{Pt}, \mathrm{CuO}$ and $\mathrm{Fe}_{3} \mathrm{O}_{4}$ ) from aqueous solutions. J. Hazard. Mater. 2015, 287, 102-110.

(53) Chen, S. G.; Yang, R. T. Theorical basis for the potential-theory adsorption-isotherms-The Dubinin-Radushkevich and DubininAstakhov equations. Langmuir 1994, 10, 4244-4249.

(54) Tan, Y.; Chen, M.; Hao, Y. High efficient removal of $\mathrm{Pb}$ (II) by amino-functionalized $\mathrm{Fe}_{3} \mathrm{O}_{4}$ magnetic nano-particles. Chem. Eng. J. 2012, 191, 104-111.

(55) Parks, G. A. Isoelectric points of solid oxides solid hydroxides and aqueous hydroxo complex systems. Chem. Rev. 1965, 65, 177198.

(56) Khan, S. S.; Mukherjee, A.; Chandrasekaran, N. Adsorptive removal of silver nanoparticles (SNPs) from aqueous solution by Aeromonas punctata and its adsorption isotherm and kinetics. Colloids Surf., B 2012, 92, 156-160.

(57) Li, L. X. Y.; Hartmann, G.; Doblinger, M.; Schuster, M. Quantification of nanoscale silver particles removal and release from municipal wastewater treatment plants in Germany. Environ. Sci. Technol. 2013, 47, 7317-7323. 